\title{
Syntheses of procyanidin B2 and B3 gallate derivatives using equimolar condensation mediated by $\mathrm{Yb}(\mathrm{OTf})_{3}$ and their antitumor activities
}

\author{
Manato Suda, ${ }^{a}$ Miyuki Katoh, ${ }^{\mathrm{a}}$ Kazuya Toda, ${ }^{\mathrm{b}}$ Kiriko Matsumoto, ${ }^{\mathrm{b}}$ Koichiro Kawaguchi, ${ }^{\mathrm{b}}$ Sei-ichi Kawahara, ${ }^{\mathrm{c}}$ \\ Yasunao Hattori, ${ }^{\mathrm{d}}$ Hiroshi Fujii, ${ }^{* \mathrm{~b}}$ and Hidefumi Makabe*a
}

${ }^{\mathrm{a}}$ Graduate School of Agriculture, Sciences of Functional Foods, Shinshu University, 8304 Minami-minowa Kami-ina, Nagano, 399-4598, Japan

${ }^{\mathrm{b}}$ Department of Bioscience and Biotechnology, Faculty of Agriculture, Shinshu University, 8304 Minami-minowa Kami-ina, Nagano, 399-4598, Japan

${ }^{c}$ St. Cousair Co., Ltd., 1260 Imogawa, Kamiminochi, Nagano, 389-1201, Japan

${ }^{\mathrm{d} D e p a r t m e n t ~ o f ~ M e d i c i n a l ~ C h e m i s t r y, ~ K y o t o ~ P h a r m a c e u t i c a l ~ U n i v e r s i t y, ~ Y a m a s h i n a-k u, ~ K y o t o ~ 607-8412, ~ J a p a n ~}$

*Corresponding author. Tel. +81 26577 1629; fax +81 26577 1629; e-mail: hfujii@ @hinshu-u.ac.jp
*Corresponding author. Tel. +81 26577 1630; fax +81 26577 1700; e-mail: makabeh@ @hinshu-u.ac.jp

\begin{abstract}
Synthesis of procyanidin B2 and B3 gallate derivatives, 3-O-gallate, 3"-O-gallate, and 3,3"-di-Ogallate, were synthesized using equimolar condensation mediated by $\mathrm{Yb}(\mathrm{OTf})_{3}$. Synthesized compounds showed significant antitumor effects against human prostate PC-3 cell lines. Their activities were weaker than wellknown EGCG and prodelphinidin B3.
\end{abstract}

Key words: polyphenol, condensation, Lewis acid, procyanidin gallate, antitumor

Procyanidin gallates are paid attention due to their significant biological activities. ${ }^{1}$ For example, inhibitory activity of DNA polymerase ${ }^{2-4}$ and antitumor activity were reported..$^{5}$ As to the procyanidin B2 and B3 gallates, a number of isolation and biological studies have been reported; procyanidin B2 3-O-gallate (1), ${ }^{5-10} \mathrm{~B} 2$ 3"- $O$ gallate (2), ${ }^{6-9,11-17}$ B2 3,3"-O-di-gallate (3), ${ }^{12,13}$ and B3 3-O-gallte (4). ${ }^{18,19}$ Furthermore, many procyanidin gallates including various oligomer have been reported. However, it is difficult to isolate procyanidin gallates in pure state from the nature, the structural-activity relationship study (SAR study) of these compounds have not been clarified yet. Thus, synthetic studies on procyanidin gallates are very important to obtain them in pure state for the biological study. By far, the report of synthesis of procyanidin galltes are quite limited. ${ }^{2-4,20,21}$ The reported syntheses of procyanidin gallates was accomplished using Lewis acid-mediated condensation of catechin and/or epicatechin derived nucleophiles and electrophiles. The disadvantage of this reaction is that using an excess 
amount of nucleophile was necessary to avoid polymerization. So far, we have developed an efficient synthesis of procyanidin dimers through equimolar condensation of catechin nucleophiles with electrophiles using $\mathrm{Yb}(\mathrm{OTf})_{3}$ as a Lewis acid. ${ }^{22-25}$ Herein we demonstrate equimolar condensation of a catechin and/or a epicatechin nucleophile containing gallate moiety with a catechin and/or epicatechin derived electrophile and synthesis of procyanidin B2 and B3 gallates (Figure 1).

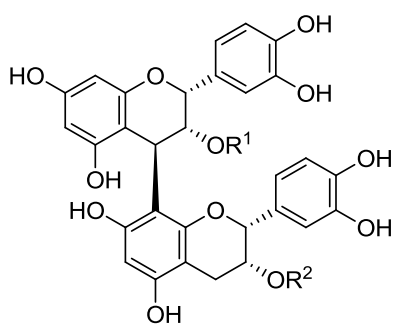

1: $R^{1}=G$ (galloyl), $R^{2}=H$

2: $R^{1}=H, R^{2}=G$

3: $R^{1}=R^{2}=G$

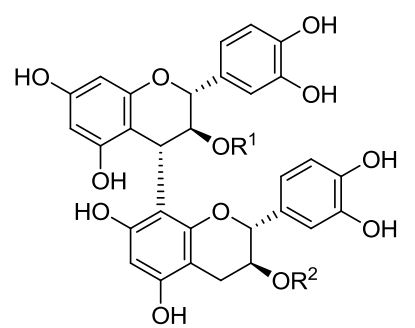

4: $R^{1}=G, R^{2}=H$

5: $R^{1}=H, R^{2}=G$

6: $R^{1}=R^{2}=G$

Figure 1. The structures of procyanidin B3 and B2 gallates (1-6).

As to the synthesis of procyanidin B2 gallates (1-3), the nucleophile 7, 8 and the electrophile $\mathbf{9}, 10$ were prepared by the reported procedure..$^{2-4,22,23}$ Equimolar condensation between nucleophile 7 and electrophile 9 using $\mathrm{Yb}(\mathrm{OTf})_{3}$ as a Lewis acid to afford 11 in $53 \%$ yield. The benzylated procyanidin B2 3"-O-gallate (12) and procyanidin B2 3,3"-O-gallate (13) were also obtained from the condensation between nucleophile 8 and electrophile 10, nucleophile 8 and electrophile 9 in $22 \%$ and $43 \%$ yields, respectively. The ${ }^{1} \mathrm{H}$ and ${ }^{13} \mathrm{C}$ NMR data of the all condensed products 11-13 were identical with the reported values. ${ }^{3}$

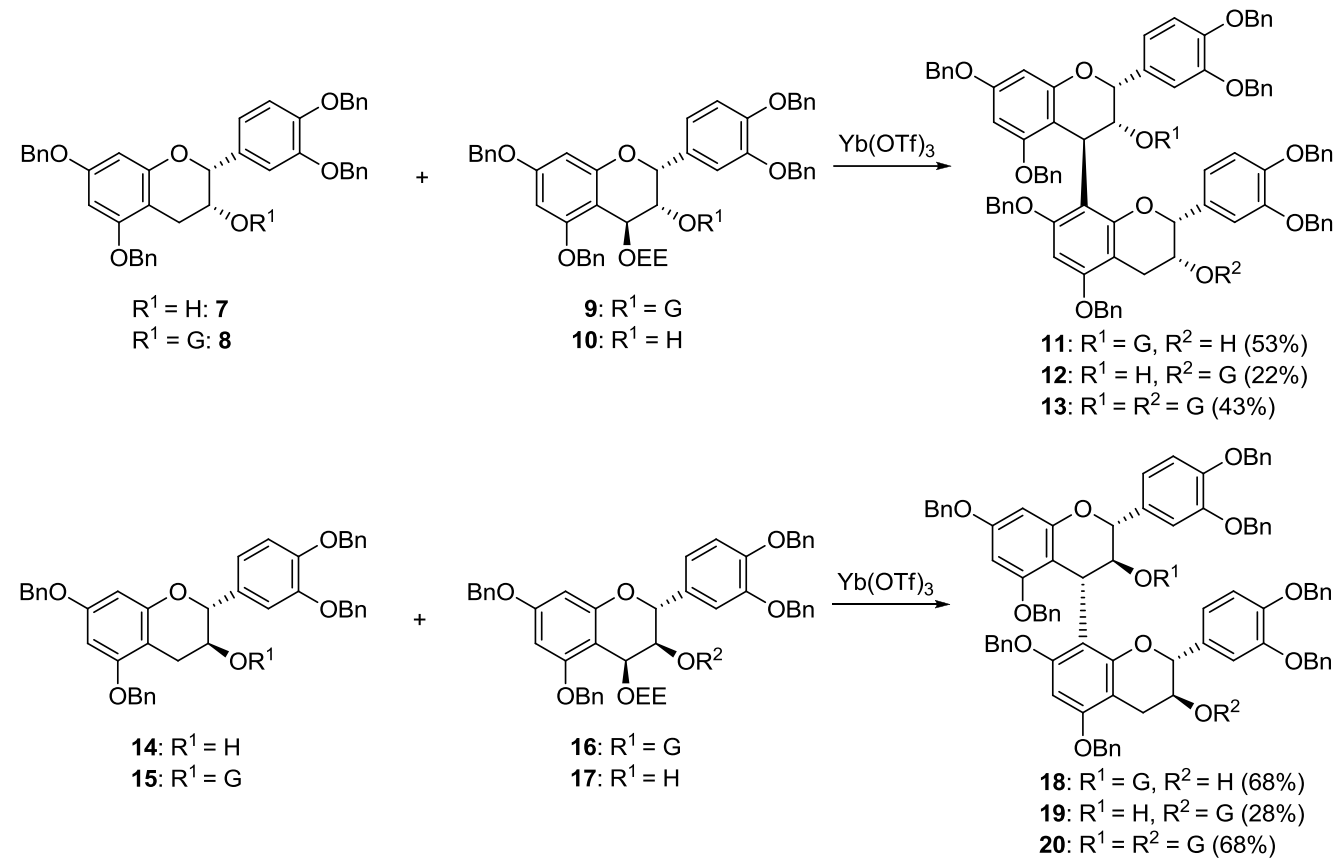

Scheme 1. Synthesis of benzylated procyanidin B2 and B3 gallates via $\mathrm{Yb}(\mathrm{OTf})_{3}$ mediated equimolar condensation.

Similarly, related compounds of the procyanidin B3 gallates were synthesized. The nucleophile 14, $\mathbf{1 5}$ and 
the electrophile 16, 17 were prepared by the reported procedure. ${ }^{2-4,22,23}$ Equimolar condensation between nucleophile 14 and electrophile 16 using $\mathrm{Yb}(\mathrm{OTf})_{3}$ as a Lewis acid to afford $\mathbf{1 8}$ in $68 \%$ yield. The benzylated procyanidin B2 3"-O-gallate (19) and procyanidin B2 3,3"-O-di-gallate (20) were also obtained from the condensation between nucleophile 15 and electrophile 17, nucleophile 15 and electrophile 16 in $28 \%$ and 68\% yields, respectively. The ${ }^{1} \mathrm{H}$ and ${ }^{13} \mathrm{C}$ NMR data of the all condensed products 18-20 were identical with the reported values (Scheme 1).,

Because the yields of condensation between 8 and 10 (22\%), 15 and 17 (28\%) were low, we investigated the esterification of benzylated procyanidin B2 (21) and B3 (22) with benzylated gallic acid (23). In the case of the esterification between 21 and 23 using EDCI, the yield of desired product 12 was only 18\% along with 11 (25\%) and 13 (15\%). On the other hand, esterification between 22 and 23 using DCC gave 19 in 65\% yield. This method improved the synthesis of 19 compared to $\mathrm{Yb}(\mathrm{OTf})_{3}$ mediated equimolar coupling (Scheme 2).

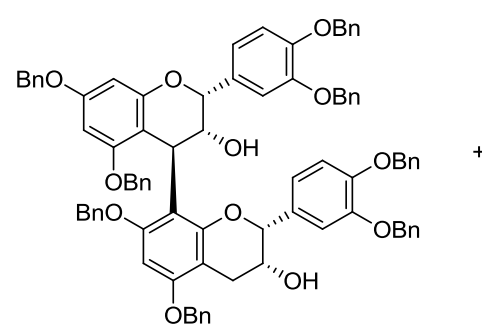

21

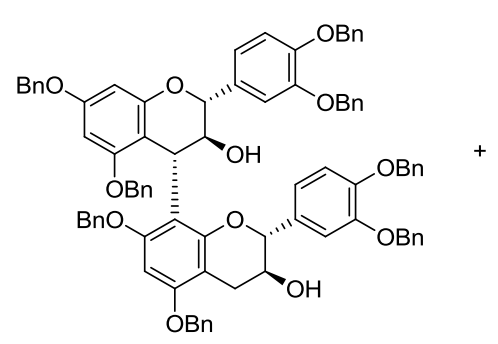

22
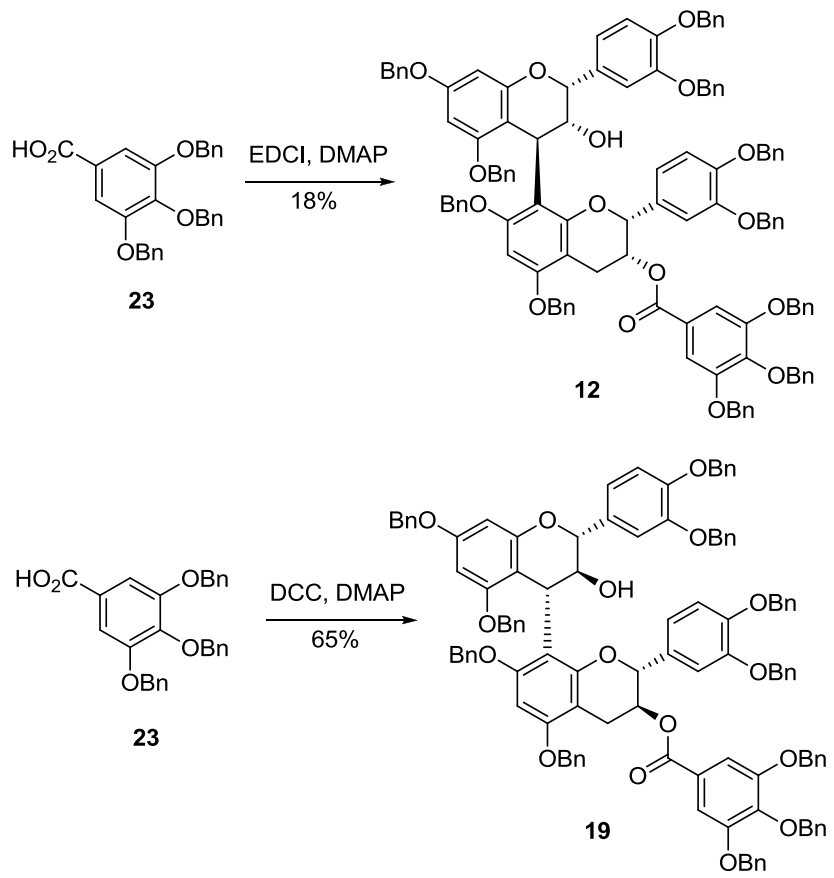

Scheme 2. Esterification of benzylated procyanidin B2 (21) and B3 (22) with benzylated gallic acid (23).

Deprotection of the benzyl ethers of 11-13 and 18-20 and subsequent lyophilization afforded 1-6 in good yield. We confirmed that lyophilized 1-6 was pure by HPLC analysis. ${ }^{26}$ The specific rotation value of synthetic 1-6 were similar to those reported values. ${ }^{2,3}$ We found that low concentration was necessary for measurements because of low degree of solubility when acetone was used as a solvent. Thus, we supplied the data of optical rotation values using $\mathrm{MeOH}$ as a solvent in the supplementary data. The ${ }^{1} \mathrm{H}$ and ${ }^{13} \mathrm{C} \mathrm{NMR}$ data were reported in the literature using acetone- $d_{6} \cdot{ }^{11,18,19}$ However, severe broadening of the peak was observed in the ${ }^{1} \mathrm{H}$ NMR spectra of 1-6 in our measurement. Thus we switched to use methanol- $d_{4}$ for measurement of NMR. As to the HRMS data of 1-6, we obtained satisfied results. We transfromed 1-6 into peracetate 24-29 to confirm the structures. The ${ }^{1} \mathrm{H}$ and ${ }^{13} \mathrm{C}$ NMR spectral data of peracetate 24-26 were in good agreement with the reported values. ${ }^{3}$ Peracetate 27-29 also gave satisfied ${ }^{1} \mathrm{H}$ and ${ }^{13} \mathrm{C}$ NMR data (Scheme 3). 


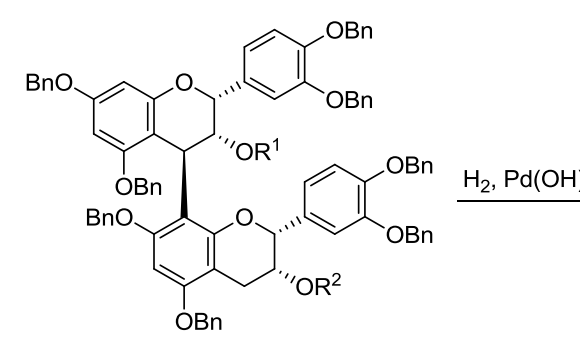

11: $R^{1}=G, R^{2}=H$

12: $R^{1}=H, R^{2}=G$

13: $R^{1}=R^{2}=G$

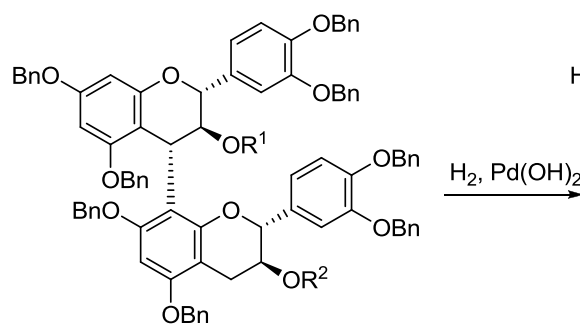

18: $R^{1}=G, R^{2}=H$

19: $R^{1}=H, R^{2}=G$

20: $R^{1}=R^{2}=G$

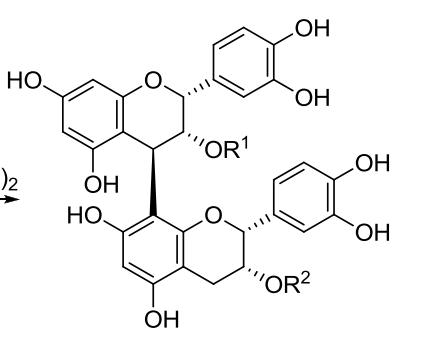

1: $R^{1}=G, R^{2}=H$ (quant.)

2: $R^{1}=H, R^{2}=G$ (quant.)

3: $R^{1}=R^{2}=G$ (quant.)

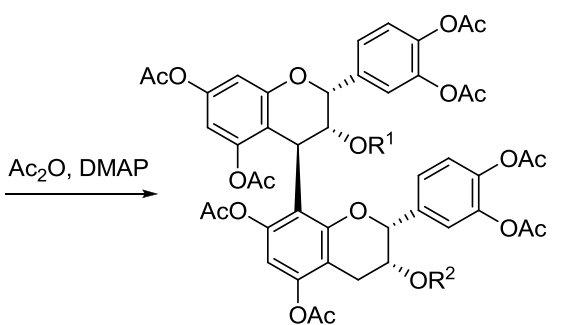

24: $R^{1}=G, R^{2}=A c(31 \%)$

25: $R^{1}=A c, R^{2}=G(36 \%)$

26: $R^{1}=R^{2}=G(28 \%)$<smiles>Oc1cc(O)c2c(c1)O[C@H](c1ccc(O)c(O)c1)[C@H](O)[C@H]2c1c(O)cc(O)c2c1O[C@H](c1ccc(O)c(O)c1)[C@H](O)C2</smiles>

4: $R^{1}=G, R^{2}=H$ (quant.)

5: $R^{1}=H, R^{2}=G$ (quant.)

6: $R^{1}=R^{2}=G$ (quant.)

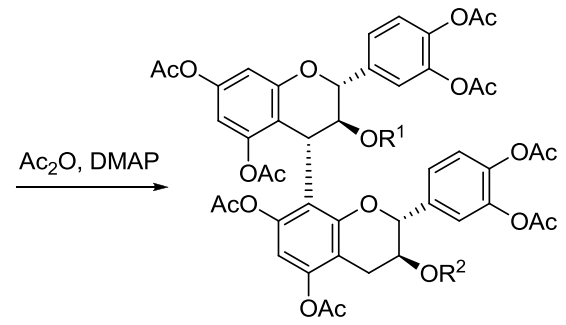

27: $R^{1}=G, R^{2}=A c(56 \%)$

28: $R^{1}=A c, R^{2}=G(42 \%)$

29: $R^{1}=R^{2}=G(10 \%)$

Scheme 3. Synthesis of 1-6 and their peracetate 24-29.

Our interest was focused on examining the antitumor activities of the newly synthesized procyanidin B2 and B3 gallates. The synthesis of procyanidin B2 3-O-gallate (1), procyanidin B2 3"- $O$-gallate (2), procyanidin B2 3,3"-O-gallate (3), procyanidin B3 3-O-gallate (4), procyanidin B3 3"- $O$-gallate (5), and procyanidin B2 3,3"-Ogallate (6) allowed us to obtain sufficient quantities of purified compounds to screen against PC-3 prostate cancer cell lines together with procyanidin B2 (PCB2), B3 (PCB3) and prodelphinidin B3 (PDB3) which were prepared by us previously (Figure 2). ${ }^{22-25,27}$<smiles>O=C(O)C1Cc2c(O)cc(O)cc2O[C@H]1c1cc(O)c(O)c(O)c1</smiles>

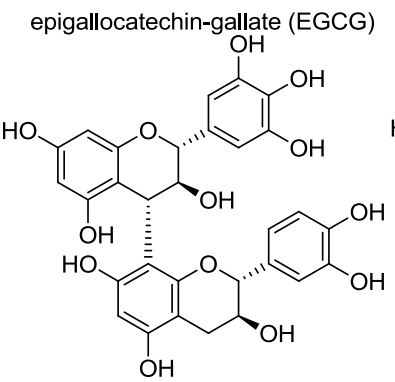

prodelphinidin B3 (PDB3)<smiles>Oc1cc(O)c2c(c1)O[C@H](c1ccc(O)c(O)c1)[C@H](O)[C@H]2c1c(O)cc(O)c2c1O[C@H](c1ccc(O)c(O)c1)C[C@H]2O</smiles>

procyanidin $\mathrm{B} 3$ (PCB3)<smiles>[Z20][C@@H]1[C@@H](c2ccc(O)c(O)c2)Oc2cc(O)cc(O)c2[C@H]1c1c(O)cc(O)c2c1O[C@@H](c1ccc(O)c(O)c1)[C@@H]([R2])C2</smiles>

1: $R^{1}=G, R^{2}=H$ 2: $R^{1}=H, R^{2}=G$ 3: $R^{1}=R^{2}=G$<smiles>Oc1cc(O)c2c(c1)O[C@H](c1ccc(O)c(O)c1)[C@H](O)C2c1c(O)cc(O)c2c1O[C@H](c1ccc(O)c(O)c1)[C@H](O)C2</smiles>

procyanidin $\mathrm{B} 2$ (PCB2)<smiles>[R2]O[C@H]1Cc2c(O)cc(O)c([C@@H]3c4c(O)cc(O)cc4O[C@H](c4ccc(O)c(O)c4)C3[Z20])c2O[C@H]1c1ccc(O)c(O)c1</smiles>

4: $R^{1}=G, R^{2}=H$

5: $R^{1}=H, R^{2}=G$

6: $R^{1}=R^{2}=G$

Figure 2. The structures of test compounds for PC-3 prostate anticancer activity. 
Results were obtained by cell count measurement. Epigallocatechin gallate (EGCG) was used as a positive control. As shown in Figure 3, procyanidin B2 3-O-gallate (PCB2 3-OG, 1), procyanidin B2 3"-O-gallate (PCB2 3"-OG, 2), procyanidin B2 3,3"-O-di-gallate (PCB2 3,3"-ODG, 3), procyanidin B3 3-O-gallate (PCB3 3-OG, 4), procyanidin B3 3"-O-gallate (PCB3 3"-OG, 5), and procyanidin B2 3,3"-O-di-gallate (PCB3 3,3"-ODG, 6) exhibited significant cytotoxic activity. The activities of procyanidin B2 3,3"-O-di-gallate (3) and procyanidin B2 3,3"-O-di-gallate (6) were stronger than those of mono-substituted gallate compounds. However, a comparison of the potencies of $\mathbf{3}$ and $\mathbf{6}$ with prodelphinidin B3 showed that the cytotoxic effects were a little bit weaker. This finding suggests that esterified pyrogallol moiety shows weaker activity compared to the compounds such as PDB3 (Figure 3).

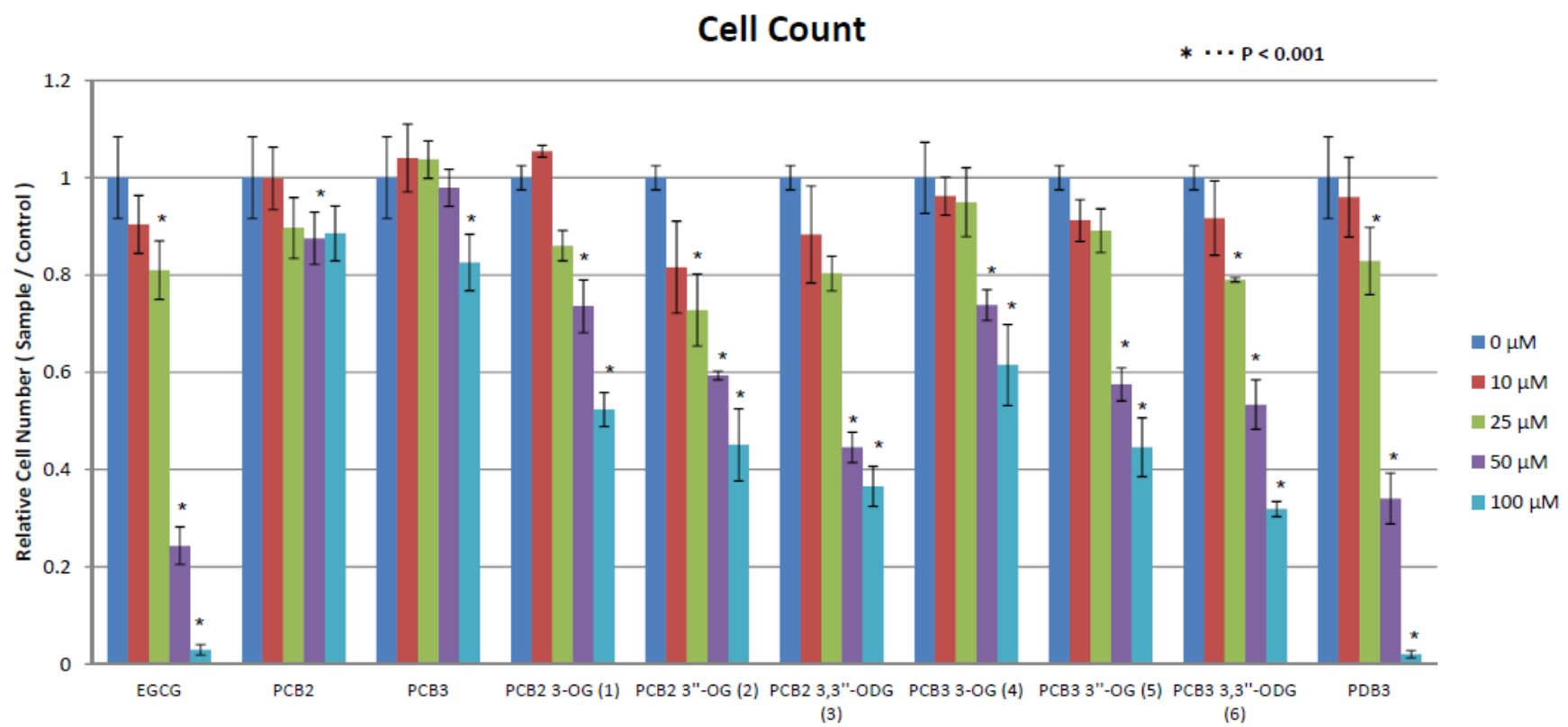

After treatment of cells with PCB2 3-OG (1), PCB2 3"-OG (2), PCB2 3,3"-ODG (3), PCB3 3-OG (4), PCB3 3"-OG (5), and PCB3 3,3”ODG (6) for $48 \mathrm{~h}$, the cell proliferation was determined by cell count as shown in supplementary data. The values were represented as the rate of inhibition of cell proliferation by the treated sample compared to the untreated control (vehicle). Values are means \pm S.Ds. for three independent experiments. Asterisks indicated a significant difference between the control- and test-compound-treated cells, as analyzed by Student's test $(\mathrm{p}<0.001)$.

Figure 3. Effects of various concentrations of test compounds on cell proliferation.

In summary, syntheses of procyanidin B2 3-O-gallate (1), procyanidin B2 3"-O-gallate (2), procyanidin B2 3,3"$O$-di-gallate (3), procyanidin B3 3-O-gallate (4), procyanidin B3 3"-O-gallate (5), and procyanidin B2 3,3"-O-digallate (6) were achieved via equimolar condensation of a catechin and/or a epicatechin nucleophile containing gallate moiety with a catechin and/or epicatechin derived electrophile. As to the synthesis of $\mathbf{5}$, esterification between benzylated procyanidin B2 (22) and benzylated gallic acid (23) using DCC was effective. The antitumor activities of 1-6 suggested that these compounds showed significant cytotoxic activity but weaker than EGCG and prodelphinidin B3. 


\section{Acknowledgements}

This work was supported in part by Grant-in-Aid for Scientific Research from the Ministry of Education, Science, Culture, Sports, and Technology of Japan (22570112 to H. F.) and by Grant from Uehara Memorial Foundation (to H. F.). We also thank Prof. Dr. Toshiyuki Kan for providing EGCG.

\section{Supplementary data}

Supplementary data associated with this article can be found, in the online version, at http://dx.doi

\section{References and notes}

1. Harbone, J. B.; Baxter, H. The Handbook of Natural Flavonoids; John Wiley \& Sons; NY, 1999.

2. Saito, A.; Emoto, M.; Tanaka, A.; Doi, Y.; Shoji, K.; Mizushina, Y.; Ikawa, H.; Yoshida, H.; Matsuura, N.; Nakajima, N. Tetrahedron 2004, 60, 12043.

3. Saito, A.; Mizushina, Y.; Ikawa, H.; Yoshida, H.; Doi, Y.; Tanaka, A.; Nakajima, N. Bioorg. Med. Chem. 2005, 13, 2759.

4. Sakuda, H.; Saito, A.; Mizushina, Y.; Yoshida, H.; Tanaka, A.; Nakajima, N. Heterocycles 2006, 67, 175.

5. Agarwal, C.; Veluri, R.; Kaur, M.; Chou, S. -C.; Thompson, J. A.; Agarwal, R. Carcinogenesis 2007, $28,1478$.

6. Monagas, M.; Gomez-Cordoves, C.; Bartolome, B.; Laureano, O.; Ricardo-da-Silva, J. M. J. Agric. Food Chem. 2003, 51, 6475.

7. Jordao, A. M.; Ricardo-Da-Silva, J. M.; Laureano, O. Vitis 2001, 40, 17.

8. Sun, B.; Belchior, G. P.; Ricardo-da-Silvab, J. M.; Spranger, M. I. J. Chromatogr. A 1999, 841, 115.

9. Dallas, C.; Ricardo-Da-Silva, J. M.; Laureano, O. Vitis 1995, 34, 51.

10. Ricardo-Da-Silva, J. M.; Rigaud, J.; Cheynier, V.; Cheminat, A.; Moutounet, M. Phytochemistry 1991, 30, 1259.

11. Nonaka, G. -I.; Nishioka, I.; Nagasawa, T.; Oura, H. Chem. Pharm. Bull. 1981, 29, 2862.

12. Nonaka, G. -I.; Kawahara, O.; Nishioka, I. Chem. Pharm. Bull. 1983, 31, 3906.

13. Anke, J.; Petereit, F.; Engelhardt, C.; Hensel, A. Nat. Prod. Res. 2008, 22, 1237.

14. Trotin, F.; Moumou, Y.; Vasseur, J. Phytochemistry 1993, 32, 929.

15. Moumou, Y.; Trotin F.; Vasseur, J.; Vermeersch, G.; Guyon, R.; Dubois, J.; Pinkas, M. Planta Med. 1992, 58, 516.

16. Liang, X.; Xiao, P. Planta Med. 1989, 55, 402.

17. Boukharta, M.; Girardin, M.; Metche, M. J. Chromatogr. 1988, 455, 406.

18. Tanaka, T. Nonaka, G. -I.; Nishioka, I. Phytochemistry 1983, 22, 2575.

19. Cho, Y. -J. Agric. Chem. Biotechnol. 2000, 43, 273. 
20. Tückmantel, W.; Kozikowski, A. P.; Romanczyk, Jr. L. J. J. Am. Chem. Soc. 1999, 121, 12073.

21. Kozikowski, A. P.; Tückmantel, W.; Hu, Y. J. Org. Chem. 2001, 66, 1287.

22. Mohri, Y.; Sagehashi, M.; Yamada, T.; Hattori, Y.; Morimura, K.; Kamo, T.; Hirota, M.; Makabe, H. Tetrahedron Lett. 2007, 48, 5891.

23. Mohri, Y.; Sagehashi, M.; Yamada, T.; Hattori, Y.; Morimura, K.; Hamauzu, Y.; Kamo, T.; Hirota, M.; Makabe, H. Heterocycles 2009, 79, 549.

24. Oizumi, Y.; Mohri, Y.; Hirota, M.; Makabe, H. J. Org. Chem. 2010, 75, 4884.

25. Katoh, M.; Oizumi, Y. Mohri, Y.; Hirota, M.; Makabe, H. Lett. Org. Chem., 2012, 9, 233.

26. HPLC measurement condition: column; InertSustain $\mathrm{C} 18250 \times 4.6 \mathrm{~mm}$ Waters, eluent $0.2 \% \mathrm{CH}_{3} \mathrm{COOH}-$ $\mathrm{CH}_{3} \mathrm{OH}$, flow rate: $0.8 \mathrm{~mL} / \mathrm{min}$, detection: UV $280 \mathrm{~nm}$, retention time; procyanidin B2 3-O-gallate (1): 16.58 min, procyanidin B2 3"-O-gallate (2): 18.14 min, procyanidin B2 3,3"-O-gallate (3): 20.50 min., procyanidin B3 3-O-gallate (4): $17.87 \mathrm{~min}$, procyanidin B3 3"-O-gallate (5): $25.18 \mathrm{~min}$, procyanidin B2 3,3"-O-gallate (6): $24.86 \mathrm{~min}$.

27. Fujii, W.; Toda, K.; Kawaguchi, K.; Kawahara, S.-i.; Katoh, M.; Hattori, Y.; Fujii, H.; Makabe, H. Tetrahedron 2013, 69, 3543. 